\title{
Temporal genetic dynamics of reintroduced and translocated populations of the endangered golden lion tamarin (Leontopithecus rosalia)
}

\author{
Andreia Magro Moraes ${ }^{1} \cdot$ Carlos R. Ruiz-Miranda $^{1} \cdot$ Milton Cezar Ribeiro $^{2} \cdot$ \\ Adriana D. Grativol ${ }^{1}$ Carolina da S. Carvalho ${ }^{2} \cdot$ James M. Dietz $^{3}$. \\ Maria Cecília M. Kierulff ${ }^{4}$ Lucas A. Freitas ${ }^{5} \cdot$ Pedro M. Galetti Jr ${ }^{6}$
}

Received: 23 June 2016 / Accepted: 17 February 2017 / Published online: 25 March 2017

(C) Springer Science+Business Media Dordrecht 2017

\begin{abstract}
Reintroductions-captive-born animals introduced into the species' original distribution area-and translocations-free-living animals transferred to another location within the historical distribution area-are important conservation strategies for endangered species. Genetic analyses of 239 individuals from unmanaged, translocated and reintroduced populations of Leontopithecus rosalia were performed using 14 microsatellites. These samples were collected during two periods: (a) 1996-1997 (historic), when individuals were translocated and reintroduced into forest fragments in the lowland Atlantic Forest, and (b) 2007-09 (recent). We hypothesized that effective population size and genetic diversity would increase over
\end{abstract}

Electronic supplementary material The online version of this article (doi:10.1007/s10592-017-0948-4) contains supplementary material, which is available to authorized users.

Andreia Magro Moraes

andreiamagro@uenf.br; andreiamagro@yahoo.com.br

1 Programa de Pós-graduação em Ecologia e Recursos Naturais, Universidade Estadual do Norte Fluminense (UENF), Campos dos Goytacazes, Rio de Janeiro 28013-602, Brazil

2 Departamento de Ecologia, Universidade Estadual Paulista (UNESP), Rio Claro, São Paulo 13506-900, Brazil

3 Save The Golden Lion Tamarin, Silver Spring, MD, USA

4 Programa de Pós-graduação em Biodiversidade Tropical, Centro Universitário Norte do Espírito Santo (CEUNES), Universidade Federal do Espírito Santo (UFES), São Mateus, Espírito Santo 29932-540, Brazil

5 Departamento de Genética, Universidade Federal do Rio de Janeiro, Rio de Janeiro 21.941-617, Brazil

6 Departamento de Genética e Evolução, Universidade Federal de São Carlos (UFSCar), São Carlos, São Paulo 13565-905, Brazil time and that these management strategies would affect the resulting population genetic structure. We found trends indicating that the effective population size at the translocation site increased while that at the reintroduction sites diminished over time. The inbreeding coefficient of the translocated population diminished over time (from 0.38 to 0.03$)$ and was much lower than that of the native $(0.29)$ and reintroduced $(0.13)$ recent populations. We observed a greater genetic admixture among the reintroduced sites on the historic sampling, as well as a strong genetic structure at the translocation site. In the recent sampling, the population structuring became more site-related suggesting low or inconsistent gene flow between sampling sites. This research highlights how conservation management decisions have an important influence on the genetic outcome of translocations and reintroductions. Future conservation planning should consider population genetic monitoring before and after management measures and maintain population connectivity thereafter to avoid the negative effects of a population size reduction.

Keywords Genetic management - Temporal genetic sampling · Conservation genetics - Microsatellite ·

Endangered species

\section{Introduction}

Reintroductions (captive-born animals introduced into the species' original distribution area) and translocations (free-living animals transferred to another location within the historical distribution area) (Kleiman 1989) are strategies useful to reverse the decline of endangered species and avert extinction (Griffith et al. 1989; Kleiman 1989; Fischer and Lindenmayer 2000; Seddon et al. 2007; IUCN/SSC 
2013). The objective of these conservation strategies is to establish viable populations over time by increasing population size of new or existing populations and by increasing or maintaining genetic diversity (Griffith et al. 1989; Kleiman 1989; Sigg et al. 2005). Since reintroductions emerged as a conservation option, the number of reintroduced and translocated animal species has increased (for review, see Fischer and Lindenmayer 2000; Seddon et al. 2007), the same occurring for the number of successful programs (e.g., Parker 2008; Michaelides et al. 2015; Mowry et al. 2015).

Two of the main goals of translocation and reintroduction programs are to increase genetic diversity and to counteract the effects of inbreeding depression in small populations (IUCN/SSC 2013). Due to these putative genetic outcomes, several studies have focused on the genetic effects of reintroduction or translocation on genetic diversity, for example Notiomystis cincta (Brekke et al. 2011), Mustela nigripes (Cain et al. 2011), Vulpes velox (Cullingham and Moehrenschlager 2013; Sasmal et al. 2013), Psittacula echo (Tollington et al. 2013), and Gongylomorphus bojerii (Michaelides et al. 2015). Few of these studies have used more than one sampling period to characterize the genetic diversity of these managed species (e.g., Cullingham and Moehrenschlager 2013; Tollington et al. 2013), which makes it difficult to monitor the consequences of reintroduction and translocation over time. Genetic monitoring over time is especially important for the planning of management strategies that will guarantee persistence of wild animals, particularly when they were reintroduced or translocated to a fragmented habitat (De Barba et al. 2010). Nevertheless, these measurements are rarely available.

The golden lion tamarin, Leontopithecus rosalia, provides an example of successful reintroductions and translocations. It is the only primate whose threat status has improved (from "critically endangered" to "endangered", Kierulff et al. 2008) through conservation efforts supported by translocations and reintroductions (Procópio-de-Oliveira et al. 2008). L. rosalia is considered a model for similar conservation programs, particularly those developed for threatened species and/or Neotropical arboreal primates. One of the goals of the translocation and reintroduction of L. rosalia was to increase and recover the genetic diversity of wild populations (Kierulff et al. 2002). Yet, the consequences of these interventions for genetic diversity have not been quantified at the molecular level. This test case provides an opportunity to assess temporal and spatial genetic processes in a species reestablished via reintroductions and translocations into a fragmented landscape.

The aim of the present research was to assess whether the conservation programs supported by reintroduction and translocation were effective in increasing and recovering genetic diversity and, consequently, in the conservation of this endangered species. To achieve this, we assessed the genetic variability within and between (a) unmanaged wild (native), (b) translocated, and (c) reintroduced $L$. rosalia populations sampled in fragments of the Atlantic Forest with varied degrees of habitat loss and fragmentation over two time periods. Although this is a fairly limited timeframe to observe changes in genetic diversity $(\leq 2$ generations), two study periods generating genetic indices are more robust to evaluate management strategies than a single sampling period (De Barba et al. 2010; Habel et al. 2014). We hypothesized that (i) the effective population size $\left(N_{e}\right)$ would increase over time as field surveys indicated a population increase, (ii) the genetic diversity would increase in accordance with the expectation for the effective population size, and (iii) the translocated and reintroduced populations would undergo genetic structuring due to founder effects, and the subsequent population isolation caused by habitat fragmentation. On the other hand, we expected that the native population would remain as a single population over time and distinct from the other populations due to two factors: it was not genetically managed and it remained isolated from the other populations.

\section{Methods}

\section{The golden lion tamarin as a model species}

The golden lion tamarin is an endangered, small arboreal primate-average body mass 598-620 g (Dietz et al. 1994) —endemic to the Atlantic Forest, Rio de Janeiro State, Brazil, and threatened with extinction (Kierulff et al. 2008). Their social system consists of small family groups (3-14 individuals) with cooperative breeding and a typically monogamous mating system with occasional polygamy (Baker et al. 1993, 2002; Dietz and Baker 1993). Tamarins reach sexual maturity between 18 and 24 months of age (Dietz et al. 1994; Baker et al. 2002), and both sexes disperse with bias toward male dispersal (Baker and Dietz 1996; Baker et al. 2002). Successful reproduction is usually achieved around 4 years of age; generation time varies between 6 and 7 years (Holst et al. 2006).

In 1964, L. rosalia was included in Brazil's first list of threatened species. In 1975, estimates suggested less than 400 individuals remained in the wild (Coimbra-Filho and Mittermier 1977). At this time, L. rosalia occurred in only two regions along São João River Basin (SJRB), Rio de Janeiro state (RJ), Brazil: Poço das Antas Biological Reserve (PDA) and the private forest fragments in northwestern SJRB (Fig. 1). These small populations were considered incapable of sustaining themselves over time without demographic intervention and the restoration of forest habitat (Kleiman et al. 1986). Therefore, a long-term 


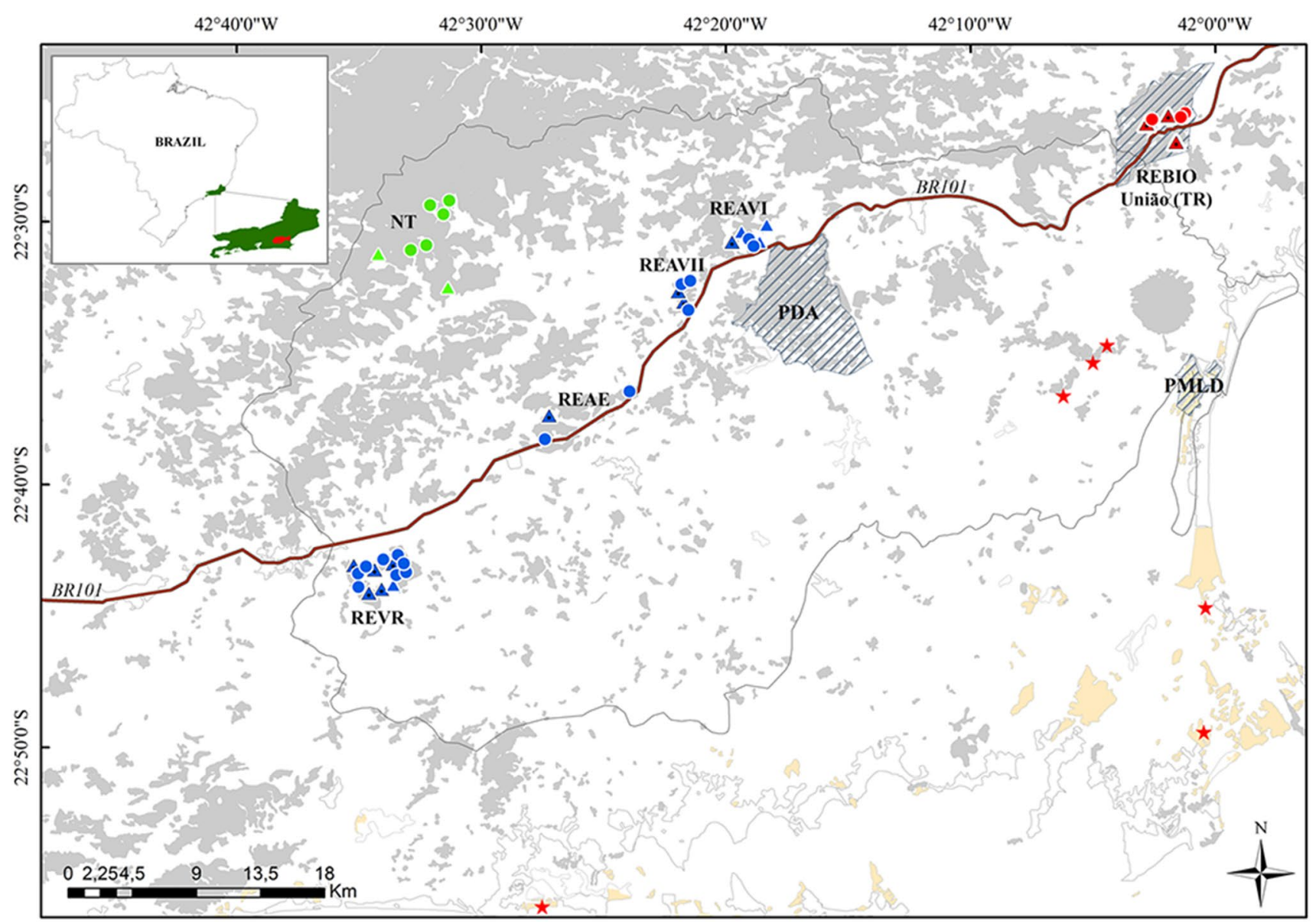

Fig. 1 Current geographic distribution of Leontopithecus rosalia in Rio de Janeiro state, Brazil. The largest polygon indicates the São João River Basin. The dashed polygons indicate fully protected Biological Reserves: REBIO União, PDA and PMLD. In gray are lowland and gallery forests and beige are restinga forests. Symbols indicate the location of sampled social groups. Blue represents the

conservation program began in 1981 and included, among other measures, (i) the reintroduction of captive animals in SJRB, and (ii) the translocation of wild isolated social groups to a continuous forest of a private farm, currently protected as União Biological Reserve (REBIO União) (Kleiman et al. 1986; Beck et al. 1991; Kierulff 2000; Kierulff et al. 2002).

In 1984, the reintroduction program for L. rosalia started based on criteria including the number of individuals in captivity, habitat suitable for the species, and the necessity of increasing genetic diversity of the wild population. Between 1984 and 2000, 147 individuals born in captivity were reintroduced into the wild. The reintroduced population had a pedigree lineage distribution equivalent to a captive population (Ballou et al. 2002; Mickelberg 2011). The individuals were reintroduced in social groups in forest fragments uninhabited by and distant from other areas occupied by the species. Generally, one social group was reintroduced (RE), red the translocated (TR), and green the native (NT) social groups. Circles represent social groups sampled in the recent and triangles in the historic time periods. The red stars represent the locations of translocated social groups before management. (Color figure online) (Source: S.O.S. Mata Atlântica)

reintroduced per forest fragment, except in large fragments (e.g. REVR in Fig. 1). By 1997, 95\% of the individuals were reintroduced. However, only $14 \%$ of the captive-born reintroduced animals remained alive at this date. When the reintroductions were concluded, the number of reintroduced $L$. rosalia and their offspring born in the wild reached 359 individuals (Kierulff et al. 2002).

Translocations began later than reintroductions. The decision to translocate wild individuals of $L$. rosalia was made after a regional-wide survey done between 1990 and 1992 detected small populations living in small fragments $\left(0.2-2 \mathrm{~km}^{2}\right.$ ), with high risk of total habitat loss (Kierulff and Rylands 2003). Between 1994 and 1997 all 42 tamarins from six social groups inhabiting four isolated coastal forest fragments were translocated to REBIO União (Fig. 1). This location was chosen due to its large size (around $2500 \mathrm{ha}$ ) of preserved forest uninhabited by and distant from other areas occupied by the species (Kierulff and 
Procópio-de-Oliveira 1996; Kierulff 2000). Even though the landscapes and timescales of the translocations and reintroductions were different, this study is a heuristic comparison of two different conservation actions on genetic diversity.

\section{Study area and sample collection}

The study area is located within the current $L$. rosalia distribution: SJRB and REBIO União (Fig. 1). SJRB is characterized by remnants of Atlantic Forest, a highly fragmented and threatened biome (Ribeiro et al. 2009). REBIO União is adjacent to SJRB and currently comprises 2548 ha. The forests of both conservation units (SJRB and REBIO União) are divided in two sections by the BR 101 federal highway (ICMBio 2016). The vegetative cover is taller and the mean linear distance between fragments is less in the northern part than in the southern portion of BR 101 (Procópio-de-Oliveira et al. 2008). The descendant generations of the reintroduced captive-born animals as well as the unmanaged (native) L. rosalia are distributed throughout SJRB; the descendant generations of the translocated wild groups are distributed throughout REBIO União (Holst et al. 2006).

The geographic locations of the native, reintroduced, and translocated social groups sampled in this study in 1996-1997 (hereafter referred to as 'historic'), and in 2007 and 2009 (hereafter referred to as 'recent') are given in Fig. 1. In the historic period we sampled the reintroduced individuals and their descendants, and the translocated individuals; while in the recent period only descendant individuals of both conservation strategies were sampled. We collected hair samples at six sampling sites. One site contained social groups of native individuals (NT), one site contained social groups of translocated individuals (TR), and four sites contained social groups of reintroduced individuals (RE). Reintroduced sites were further classified according to their geographic locations: REAE (Andorinha-Estreito fragment in the region of Imbaú); REAVI (São Francisco and Igarapé fragments, Aldeia Velha region); REAVII (Vale do Cedro fragment, also Aldeia Velha region); and, REVR, known as Rio Vermelho, which is a large and isolated forest fragment (1740 ha) containing approximately 20 social groups. Two fragments (PDA and Parque Municipal do Mico-Leão-Dourado-PMLD) both with known native animals were not sampled (Fig. 1).

We collected hair samples from 239 individuals from around 65 social groups; some of them were resampled between the study periods (Fig. 1). Eighty-two individuals were from the historic period, and 152 individuals were from the recent period. For REAE, additional samples $(n=5)$ were included from an intermediate period (2003). Animal capture followed the protocol described in Dietz et al. (1994). Hair samples of animals were collected by the Golden Lion Tamarin Association (Associação MicoLeão-Dourado-AMLD) field team over consecutive years and stored in silica. We selected the individuals and sampling sites for this study with the assistance of AMLD field records, which identify the individual, sex, age or age category, date of birth, date of reintroduction and the social group of origin in a given period.

A minimum number of sampled individuals were defined using accumulation curves based on the expected heterozygosity for all 14 microsatellite loci in each sampling site. Through these accumulation curves, we evaluate whether the sample size in each site would give a good estimate of genetic indices. We carried out accumulation curves by random sampling from one to the total number of sampled individuals in each site using 1000 permutations. In each permutation for a given number of sampled individuals, we estimated the expected heterozygosity and thus built the accumulation curves. We observed equity in estimates of expected heterozygosity when we sampled five or more individuals per sample site (Fig. S1). This analysis was carried out in R 3.2.2 software (R code in Supplementary Material).

\section{DNA extraction and genotyping}

We extracted DNA from hair samples using DNeasy Blood and Tissue Kits (Qiagen, Valencia, CA, USA) following the manufacturer's protocol. We tested 17 microsatellites developed for L. rosalia (Grativol et al. 2001), L. chrysopygus (Perez-Sweeney et al. 2005) and L. chrysomelas (Galbusera and Gillemot 2008). Three of them were monomorphicsLchu1, 2 and 5 (Galbusera and Gillemot 2008) - and were excluded from the analyses. The primers for the remaining 14 useful microsatellites were constructed with M13 tails and used in combination with an M13-labeled primer, following the protocol established by Schuelke (2000).

PCR reactions $(12 \mu \mathrm{L}$ ) contained $2 \mu \mathrm{L}$ of DNA (about $10 \mathrm{ng}), 0.46 \mathrm{pmol}$ of each reverse and M13-fluorescent primers, $0.12 \mathrm{pmol}$ of M13-tailed forward primer, $1 \times$ of the GoTaq Master Mix (Promega, Madison, WI, USA), and an addition of $0.63 \mathrm{mM}$ of $\mathrm{MgCl}_{2}$ and $0.25 \mathrm{mg} / \mathrm{mL}$ of BSA. We performed the DNA amplifications using a thermo Veriti ${ }^{\circledR}$ Thermal Cycler (Applied Biosystems, Foster City, CA, USA) under the following conditions: $5 \mathrm{~min}$ at $94^{\circ} \mathrm{C}$, 35 cycles of $30 \mathrm{~s}$ denaturation at $94^{\circ} \mathrm{C}$, annealing for $45 \mathrm{~s}$ at $55-62{ }^{\circ} \mathrm{C}$, extension for $45 \mathrm{~s}$ at $72^{\circ} \mathrm{C}$, and finally 10 cycles of $30 \mathrm{~s}$ denaturation at $94^{\circ} \mathrm{C}$, annealing for $45 \mathrm{~s}$ at $53^{\circ} \mathrm{C}$, extension for $45 \mathrm{~s}$ at $72^{\circ} \mathrm{C}$, followed by a final extension step of $10 \mathrm{~min}$ at $72^{\circ} \mathrm{C}$. PCR reactions were carried out for each locus separately, and products from one to eight loci were pooled together based on yield, size range and fluorescent dye for genotyping. The microsatellites' genotyping 
was performed in the ABI 3730XLs automatic sequencer (Applied Biosystems, Foster City, CA, USA) using GS 500 Liz size standard, and they were scored in Geneious R8 (Biomatters, Auckland, NZ). We amplified additional PCR replicates for samples with missing loci and 5\% of the samples (12) were chosen randomly to estimate the genotyping error rate and to confirm reliability. We estimated the error rate as the ratio between observed number of allelic differences and total number of allelic comparisons (Bonin et al. 2004). The individual samples with more than $30 \%$ of missing loci even after additional amplifications were removed from the analysis.

\section{Data analyses}

\section{Sampling set and genetic tests}

Because L. rosalia lives in family social groups (Baker et al. 2002) and therefore could have a genetic structure reflecting this type of social organization, we tested the effects of the presence of family members on the population structure (Anderson and Dunham 2008). Three sample sets were tested:

- Set 1 , using the full set of samples $(\mathrm{n}=239)$;

- Set 2, excluding the young individuals (aged $<2$ years) within the social groups in an attempt to reduce the influence of strongly related individuals on the results $(\mathrm{n}=188)$

- Set 3, resampling one individual per social group through bootstrapping with 1000 permutations, attempting to eliminate the bias of kinship $(n=69)$.

Table S1 shows the number of individuals of L. rosalia in each study site and period used to test the different sampling sets. The accuracy of each sample set was evaluated through the accumulation curve of the expected heterozygosity (see Study area and sample collection, above). After resampling using set 3 , at least seven sites retained a sample size below the minimum $(<5)$ (Table S1). Therefore, we considered set 3 inadequate for the analyses, and used only set 1 and set 2 . Furthermore, we retained samples for REAE from the intermediate period, represented by five available samples, because of its small sample size in the historic period $(\mathrm{n}=3)$.

We performed genetic analyses based on the management type (native, translocation, and reintroduction) and the spatial distribution of $L$. rosalia assigned as sampling sites (native, translocation, REAE, REAVI, REAVII, REVR). Thus, set 1 and set 2 were analyzed through comparison of (1) the differences between the management types, and (2) the changes that occurred within each sampling site over time. For each sample set we investigated the existence of possible errors in genotyping due to null alleles (frequency $>0.1$ ), stuttering, or allele dropout in MICRO-CHECKER 2.2.3 (Van Oosterhout et al. 2004). Null alleles occurring with low frequency $(<0.1)$ have no significant influence on the results (Carlsson 2008). We performed Hardy-Weinberg Equilibrium (HWE) tests in GENALEX version 6 (Peakall and Smouse 2006), and we corrected significant deviations from the HWE by using the Bonferroni confidence interval (Rice 1989).

\section{Temporal changes in effective population size and genetic diversity}

We estimated the effective population size $\left(N_{e}\right)$ through the use of both single sample estimates and the temporal method, as implemented in NeEstimator version 2.01 (Do et al. 2014). The single point-in-time estimates the inbreeding effective size $\left(N_{e i}\right)$ for all sites and times were generated considering random system and using the linkage disequilibrium method (LDNe) with bias correction. The LDNe method uses the correlation among alleles at unlinked loci and corrected for downward bias due to small sample sizes (Waples and Do 2008, 2010). The temporal method was applied to estimate the variance effective size $\left(N_{e v}\right)$ overall and for all sites. This method is related to allele frequency changes due genetic drift. It was based on the unbiased estimator $F_{s}$ that generally performs better than other temporal methods if the sample size is small and the allele frequency is skewed, a common feature in microsatellite data (Jorde and Ryman 2007). Generation time was set to 6 years, consistent with the generation time of $L$. rosalia (Holst et al. 2006), and estimates were generated for all possible combinations of years within sites using Plan I (Waples 2005; Jorde and Ryman 2007). We assumed census population sizes $\left(N_{c}\right)$ for all SJRB and REBIO União (1500 individuals) and for each sampling site according to Holst et al. (2006)—see Table 1.

For both single point-in-time and temporal methods, we obtained 95\% confidence intervals (CI) using a jackknife procedure (non-parametric data) and excluded allele frequencies lower than 0.02 (Do et al. 2014), because alleles that occur with low frequency may bias the results (Waples 2006). Due to the temporal methods having better precision than the moment methods (Wang 2005), and our research deals with populations in no equilibrium, our $N_{e i}$ results were considered only as tendencies over time (after Brekke et al. 2011). Following this, we calculated the $N_{e}$ to $N_{c}$ ratio to evaluate if $N_{e}$ based on the genetic data differed from that based on the population census (after Kamath et al. 2015).

Hierfstat package (Goudet 2005) was used in R 3.2.2 software (R Development Core Team 2015) to estimate allele frequencies and inbreeding coefficient $\left(F_{i s}\right)$, observed $\left(H_{o}\right)$ and unbiased $\left(H_{s}\right)$ heterozygosity, and allelic richness 
Table 1 Effective population size estimation for Leontopithecus rosalia from the São João River Basin and REBIO União using single $\left(N_{e i}\right.$, Waples and Do 2008) and temporal $\left(N_{e v}\right.$, Jorde and Ryman 2007) methods

\begin{tabular}{lllllllll}
\hline Sampling site & Year & Sample size & Census size $(\geq)$ & GT & $N_{e i}$ & $95 \%$ CI for $N_{e i}$ & $N_{e v}$ & $95 \%$ CI for $N_{e v}$ \\
\hline Native & 1996 & 12 & 75 & 1.8 & $\infty$ & 52 to $\infty$ & 50 & 21 to $\infty$ \\
Native & 2007 & 20 & & 3 & 2 to 6 & & \\
Translocated & 1997 & 33 & 200 & 2 & 3 & 2 to 3 & 10 & 6 to 23 \\
Translocated & 2009 & 50 & & & 14 & 10 to 20 & & \\
REAE & 1997 & 3 & 200 & 2 & $\infty$ & $\infty$ to $\infty$ & 13 & 5 to $\infty$ \\
REAE & 2009 & 9 & & & 7 & 3 to 16 & & \\
REAVI & 1997 & 11 & 200 & 2 & 20 & 9 to 146 & -47 & -267 to $\infty$ \\
REAVI & 2009 & 15 & & & 10 & 6 to 18 & & \\
REAVII & 1997 & 8 & 80 & 2 & 18 & 3 to $\infty$ & 104 & 12 to $\infty$ \\
REAVII & 2009 & 22 & & & 14 & 8 to 29 & & \\
REVR & 1997 & 15 & 200 & 2 & 37 & 19 to 177 & -123 & 82 to $\infty$ \\
REVR & 2009 & 36 & & & 15 & 11 to 20 & & \\
\hline
\end{tabular}

The approximate size of the sampling sites (census size $\geq$ ) is based on an estimate in Holst et al. (2006)

$G T$ generation time, $C I$ confidence interval, and $R E$ codes reintroduced sites
$(A R)$ corrected by the sample size per sampling site across time. We calculated the private allele richness $(P R)$ using HP-Rare (Kalinowski 2005), which was also corrected by the sample size per sampling site across time. We tested the data normality using Shapiro's test. Since most data differ from normal distribution, we used Kruskal Wallis test $\left(\chi^{2}\right.$ and $P$ value reported) to test the existence of significant differences in temporal genetic variation at the sampling site level and at the types of management level. We also tested the significant differences between management types in the recent period. All these analyses were performed in $\mathrm{R}$ 3.2.2 software (R Development Core Team 2015).

To quantify the genetic consequences of reintroduction and translocation, we simulated the loss of genetic diversity over 50 years, measured by the mean number of alleles per microsatellite locus $\left(N_{a}\right)$. We used BottleSim version 2.6 (Kuo and Janzen 2003) to simulate post-bottleneck population growth, using 1000 iterations and the following parameters: life-span $=16$ years; age at maturity $=4$ years; completely overlapping generations; random mating; dioecious reproduction; same sex ratio of females and males; and constant size population. We used the historic dataset to validate the simulations and the chosen parameters up to the recent period, and we proceeded with the analysis until 50 years were reached using the same historic dataset. Following this, we calculated the annual average and standard deviation of loss of alleles over 50 years in the native, translocated and reintroduced populations.

\section{Temporal genetic structure}

The Bayesian clusters analyses were conducted to investigate the genetic structure changes within and between the study periods using the STRUCTURE 2.3 software (Pritchard et al. 2000). To estimate the posterior probability that the data fit the $\mathrm{K}$ clusters hypothesis $[\mathrm{Pr}(\mathrm{X} / \mathrm{K})]$, we used 10 independent runs for $\mathrm{K}=1-\mathrm{N}$ (number maximum of $\mathrm{K}$ estimated in each test), MCMC of 1,000,000 interactions, and a burn-in period of 200,000 sets. The analysis was done without prior information from the origin population, using the models of admixture and correlated allele frequencies. We determined the number of genetic groups using the optimal value of the posterior probability $[\mathrm{K}(\mathrm{Pr}$ $(\mathrm{X} / \mathrm{K})]$, given as $\mathrm{LnP}(\mathrm{K})$ (Pritchard et al. 2000), and the modal value of $\Delta K$ (Evanno et al. 2005). These results of $K$ statistics were generated using HARVEST STRUCTURE (Earl and VonHoldt 2012).

Environmental, historical and demographic factors affect genetic structure. Therefore, we must evaluate different scenarios of $\mathrm{K}$ that explained different biological processes (Meirmans 2015). Other factors that influence the STRUCTURE results are the sample size (Kalinowski 2011), the type of sampling (Schwartz and McKelvey 2009) and the degree of kinship between individuals (Anderson and Dunham 2008). Hence, we considered the biological and historical aspects of $L$. rosalia in our interpretation of all the optimal and suboptimal values of the $\mathrm{K}$ statistic that were congruent between set 1 and set 2 . We investigated the temporal genetic structure through Bayesian clustering analyses comparing (1) the differences between sampling sites in each period and (2) the changes within each management type over the years.

\section{Results}

\section{Genetic tests}

In total, 336 alleles were compared, except for 28 alleles (two individuals) that could not be typed for double 
amplification. Another 26 alleles were typed for only one extract, but not for the other. Allelic dropout, false alleles or contaminations were not found among the 282 alleles amplified and checked. In addition, the frequency estimates of null alleles were inconsistent across the years and sites, and only the locus Lchu9 had a frequency of null alleles greater than 0.1 in more than three situations (Table S2a and S2b). Therefore, we performed analyses that both excluded and included the locus Lchu9. As there was no significant difference between the results generated with the use of all the loci and those generated while excluding the locus Lchu9, it was maintained in the analyses. Likewise, deviations from the HWE were inconsistent across the years and the sample sites, and they were observed mainly in the translocated samples in the historic and recent periods and in the reintroduced samples in the recent period (Table S3a and S3b). Because results from set 1 (using total individuals) and set 2 (excluding the young individuals, probably related to adults in the social group) were similar, and set 1 had fewer null alleles and preserved the variability of all the individuals in the sample set, we presented mainly the results of set 1 (Table S2a and S2b). The results using set 2 were also included in the Supplementary Material and when pertinent they were cited in the mainly text.

\section{Temporal changes in effective population size and genetic diversity}

The overall $N_{e v}$ estimated for $L$. rosalia was 88 individuals (CI 52-283). The estimates per sampling site by the single method showed that the $N_{e i}$ of the translocated site increased over time. In contrast, a trend to decrease over time was observed in the $N_{e i}$ of the reintroduced sites, although the confidence interval within each site in both study periods overlapped slightly, except in the REVR site (Table 1). All estimates concur that $N_{e}$ was lower than $N_{c}$, except the $N_{e v}$ estimated for REAVII site. As a consequence, low $N_{\mathrm{e}} / N_{\mathrm{c}}$ ratios were observed in overall estimate $\left(N_{\mathrm{ev}} / N_{\mathrm{c}}=0.058\right)$ and most of the sampling sites in both study periods $\left(N_{\mathrm{ei}} / N_{\mathrm{c}} \leq 0.21\right.$ and $N_{\mathrm{ev}} / N_{\mathrm{c}} \leq 0.66$ when excluding REAVII).

When comparing the management types in the recent period, the inbreeding coefficient of the translocated individuals was significantly lower than that of the native (Fig. $2 \mathrm{e}-\chi^{2}=5.93$, d.f. $=1, P$ value $=0.015$ ) and that of the reintroduced individuals (Fig. S2e, only in set $2-\chi^{2}=8.92$, d.f. $=1, P$ value $=0.003)$. The observed heterozygosity $\left(H_{o}\right)$ of the native individuals was also significantly lower than that of the translocated $\left(\chi^{2}=5.94\right.$, d.f. $=1, P$ value $\left.=0.015\right)$ and reintroduced $\left(\chi^{2}=9.77, P\right.$ value $\left.\leq 0.002\right)$ individuals (Fig. 2c). Although we observed no significant temporal variation in the global genetic diversity of the reintroduced population, when the individuals were subdivided according to their spatial distribution, we recorded significant variations: inbreeding coefficient of the REAVII site increased (Fig. 2e), while decreases were observed respectively in the $H_{o}$ and $P R$ of the REAVII (Fig. 2c) and REVR sites (Fig. S2b). We also observed significant temporal differences in the translocated (Fig. 2b, c, e) and native sites (Fig. 2c, e). $H_{o}$ increased and $F_{i s}$ decreased in the translocated site, while $H_{o}$ decreased and $F_{i s}$ increased in the native site. On the other hand $P R$ (Fig. $2 \mathrm{~b}$ and Fig. S2b) and allelic frequency (Table S4) showed the highest deficits of alleles over time in the translocated and REVR sites.

The simulation of the variation in average number of alleles until year 2045, using the dataset from the historic period and considering constant population sizes, also showed that in the first year after translocation the loss of alleles was more pronounced (rate of 0.36 alleles per year), and in the subsequent years the annual average loss of alleles was constant $(0.02 \pm 0.005)$. In the reintroduced and native populations, the average losses of alleles over years were minor, around $0.01 \pm 0.002$ and $0.002 \pm 0.001$, respectively (Fig. 3). This simulation also produced the mean number of alleles expected in the recent period, the same number as the results obtained in GENALEX using the dataset from the recent period, thereby increasing our confidence in the sampling set used.

\section{Temporal genetic structure}

The Bayesian cluster analyses in both the historic and the recent periods showed the highest values of $\mathrm{K}$ statistics when $\mathrm{K}=2$. In both the historic and the recent periods, when $\mathrm{K}=2$, the translocated populations comprised a single distinct cluster of all the other sites. The sampling sites in the historic period presented the second highest biologically significant value when $K=8$ (Table S5). For $\mathrm{K}=8$, the translocated populations were sub-structured in four clusters assigned according to their original distribution prior to translocation (Fig. 4a). When the sampling sites of the recent period were analyzed together, the wild populations of $L$. rosalia were again strongly structured in two clusters and sub-structured in three clusters (Table S5). In the recent period, the translocated individuals become more similar to each other and the reintroduced individuals also become more similar to each other (Fig. 4b).

When we investigated the Bayesian clustering within each management type and across the two periods, we did not observe a temporal genetic structure in the native population. In contrast, the translocated population was strongly structured in two clusters (historic and recent) and sub-structured in 3-5 clusters (Table S5) according to their original distribution prior to the foundation of the new population ( $K=5$, Fig. $4 c)$. Neither the reintroduced nor the native populations presented temporal 
(a)

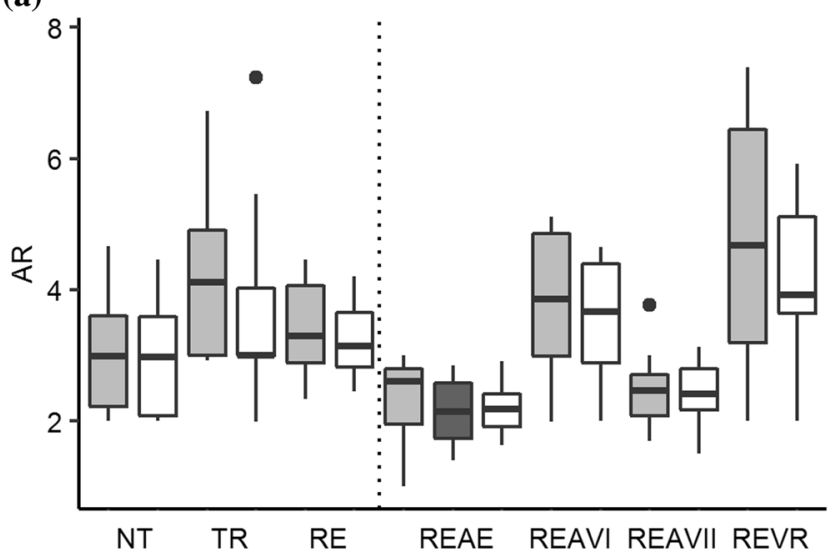

(c)

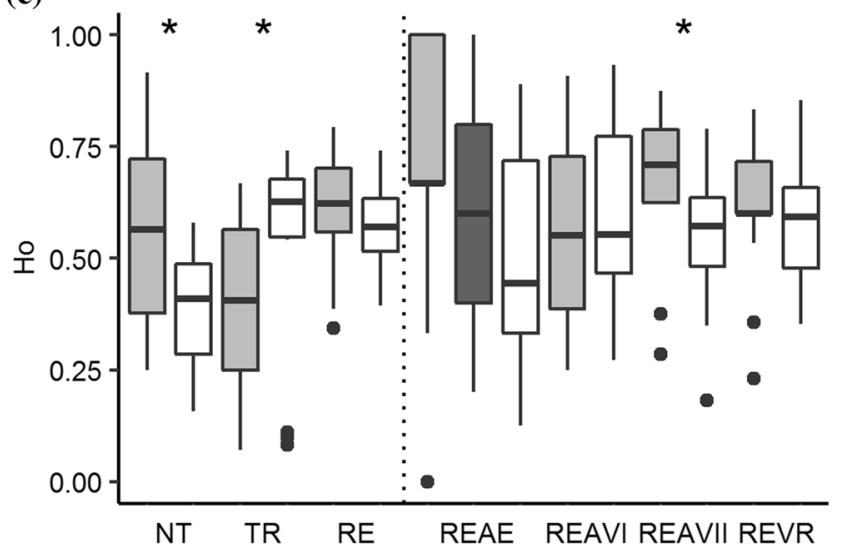

(e)

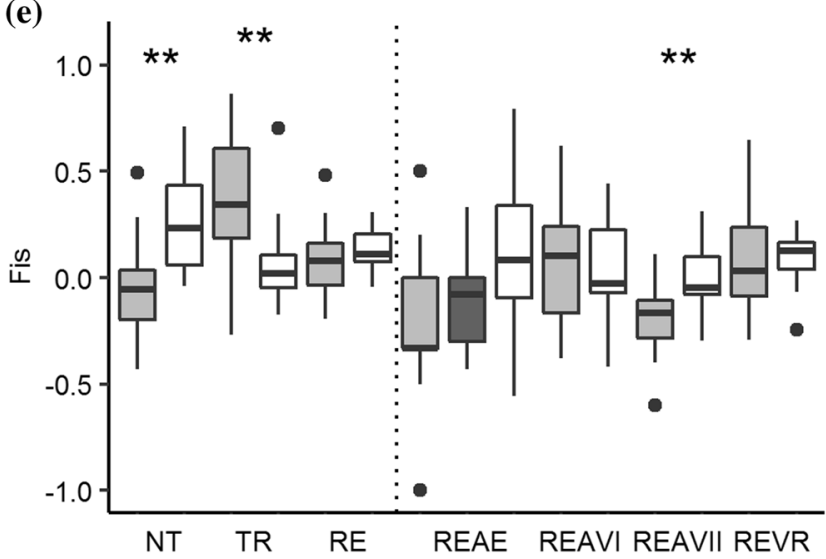

Fig. 2 Temporal changes in genetic diversity of Leontopithecus rosalia for sampling site attributes based on management types-NT, TR and RE- and on the spatial distribution of reintroduction sitesREAE, REAVI, REAVII and REVR. Indices of genetic diversity were estimated through (a) mean allelic richness-AR, b mean of allelic

differentiation. The reintroduced population, however, presented a strong structure when $\mathrm{K}=3$ (Table S5), corresponding to the release sites for the founders (Fig. 4d). (b)

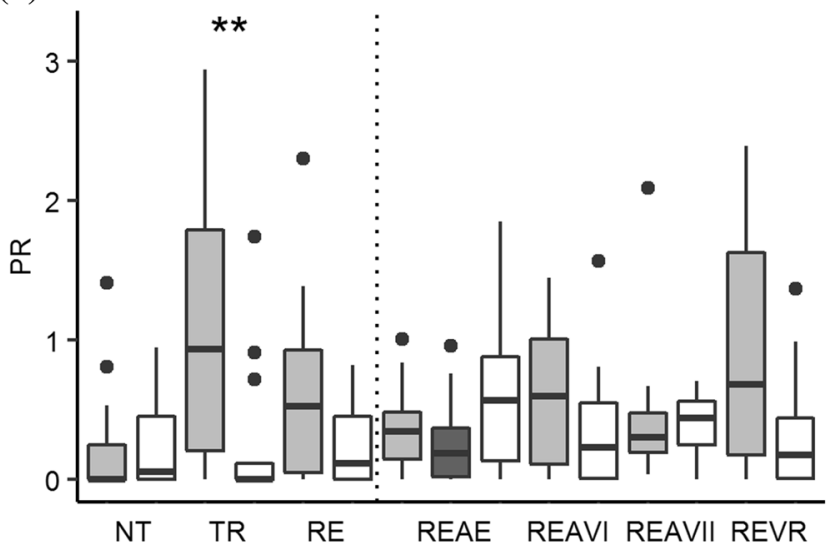

(d)

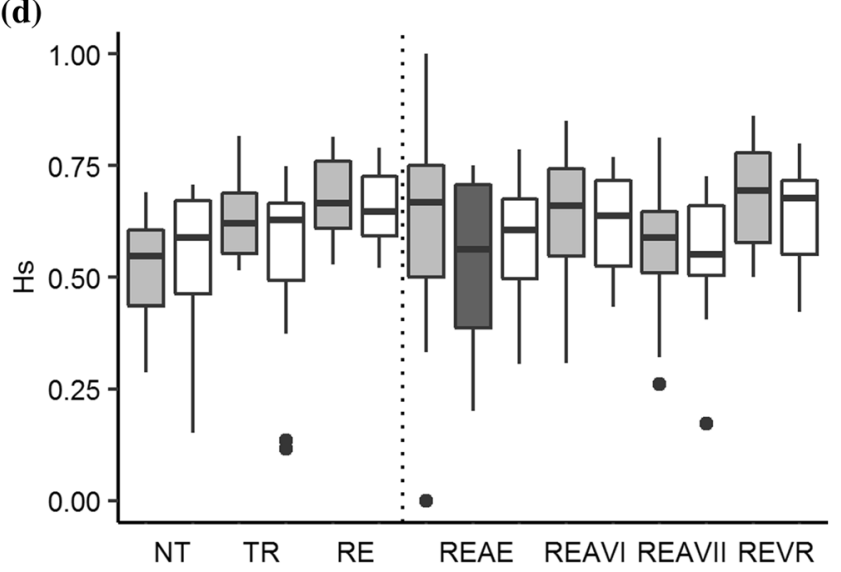

Management types

$\mathrm{NT}=$ native

$\mathrm{TR}=$ translocation

$\mathrm{RE}=$ reintroduction

Reintroduction sites

REAE

REAVI

REAVII

REVR

private richness $-P R$, c mean observed heterozygosity $-H_{o}$, d mean unbiased expected heterozygosis $-H_{s}$, and e mean inbreeding coefficient $-F_{i s}$. Color periods: gray—historical; dark gray—intermediate; and white-recent. Significant codes: $* * * 0.001, * * \leq 0.01, * \leq 0.05$

\section{Discussion}

Although the time between the two periods of study was $\leq 2$ generations, our results show temporal genetic 


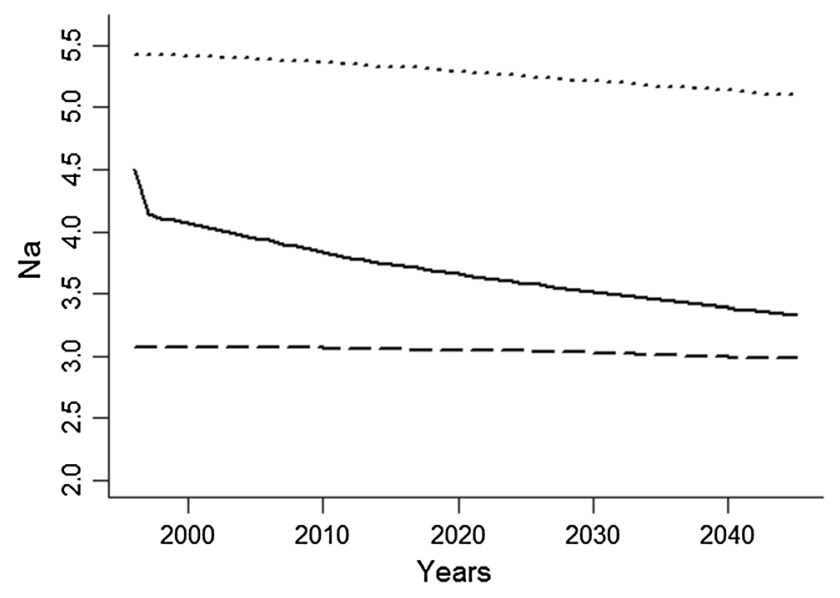

Fig. 3 Simulated loss of mean number of alleles per locus $(\mathrm{Na})$ over 50 years (1996-2045) in native (dashed line), reintroduced (dotted line) and translocated (continuous line) populations of Leontopithecus rosalia assuming constant population size through time

variation explained by the sampling sites and the management types. Despite the increase in size of the wild L. rosalia populations over time, $N_{e}$ increased only at the translocation site and tended to decrease in the reintroduction sites. The inbreeding coefficient of the translocated population diminished and the heterozygosity increased, whereas a tendency toward the opposite result was observed in the global evaluation of native and reintroduced populations. The average heterozygosity of a population is influenced not only by its founder size, but also, and more importantly, by the rate of population growth after its founding (Maruyama and Fuerst 1985). On the other hand, the translocated $L$. rosalia showed a greater loss of alleles than the reintroduced individuals. When populations experience a bottleneck effect, their allelic diversity can be lost much more rapidly than their heterozygosity, through drift (Maruyama and Fuerst 1985; Allendorf 1986).

Genetic structuring was observed among all sites, and changes in pattern were detected across the periods of time studied. A conspicuous within-site population structuring was observed in the translocated site in the founder period (historic), reflecting the mixing of isolated small populations. The population structuring became more site-related particularly in the recent period, suggesting admixture within the population as well as low or inconsistent gene flow between sampling sites after release. A similar result was observed for the swift fox, Vulpes velox (Cullingham and Moehrenschlager 2013). Probably, the temporal variation of genetic structuring resulted from a combination of the management type used during foundation of the populations, genetic drift due to the small effective population size, and the subsequent limitation of gene flow after individual translocations and reintroductions.

\section{Temporal changes in effective population size and genetic diversity}

Although the translocated and reintroduced populations of $L$. rosalia increased in size over time (Kierulff et al. 2002), their $N_{e}$ was relatively low (based on Franklin and Frankham 1998), while their genetic diversity varied on a case-by-case basis. The $N_{e i}$ at the reintroduction sites had a tendency to decrease-observed mainly in the REVR site-while the number of reproductive translocated adults increased over time. Congruently, researchers in the field reported that the number of reintroduced adults that survived after release was much lower than the cumulative number of individuals over time (see Study species, above). In contrast, the translocated animals had a high survival rate among adults post-release (annual average 82\%) (Kierulff et al. 2002).

In addition to fluctuation in population size over generations, variance in family size and unequal sex ratio also affect the $N_{e}$ of populations. $N_{e}$ typically is much lower than the estimated census population size, generally averaging about $10 \%$ of the census population size (Frankham 1995; Frankham et al. 2010). Typically, L. rosalia lives in small family groups with monogamous and occasionally polygyny mating system (Baker et al. 1993, 2002; Dietz and Baker 1993). This may explain the low $N_{e v}$ values observed in SJRB and REBIO União. Moreover, considering the overall population size estimate of 1500 individuals for L. rosalia (Holst et al. 2006; Procópio-de-Oliveira et al. 2008), the expected $N_{e}$ value is in agreement with the $N_{e v}$ range obtained (52-283). This value is far less than the 500 individuals recommended to retain the evolutionary potential of the species (Franklin and Frankham 1998).

We also found a small $N_{\mathrm{ei}} / N_{\mathrm{c}}$ ratio for all sampling sites. On the other hand, the $N_{\mathrm{ev}} / N_{\mathrm{c}}$ ratio was high in the REAVII and native sites. In the REAVII site, considering that it is a small area and is extensively monitored by AMLD, we believe that the census value is likely a reasonable estimate. In contrast, we believe that the census population size of the native site is underestimated. In fact, current estimates show that the population size in this region is much higher than expected (Morais, pers. com.). In some sites where there was no evidence of variation in the allele frequencies caused by a finite number of parents, the $N_{e}$ estimates showed infinite and/or negative values, although sampling errors (Waples and Do 2010; Do et al. 2014) and bias due to the small sample size (Waples 2006; Jorde and Ryman 2007) cannot be discarded.

Genetic diversity is lost at a rate that depends on the effective population size, rather than the census population 
Fig. 4 Structure results for Leontopithecus rosalia from forest remnants in Brazil's Atlantic Forest showing suboptimal values of $K$ between sampling sites in each study period-(a) historical and (b) recent - and within sampling sites through two different times-(c) translocated (TR) and (d) reintroduced (RE). A single vertical line represents each individual and color segments represent partitioning into K clusters. (Color figure online)

\section{(a) Historic}

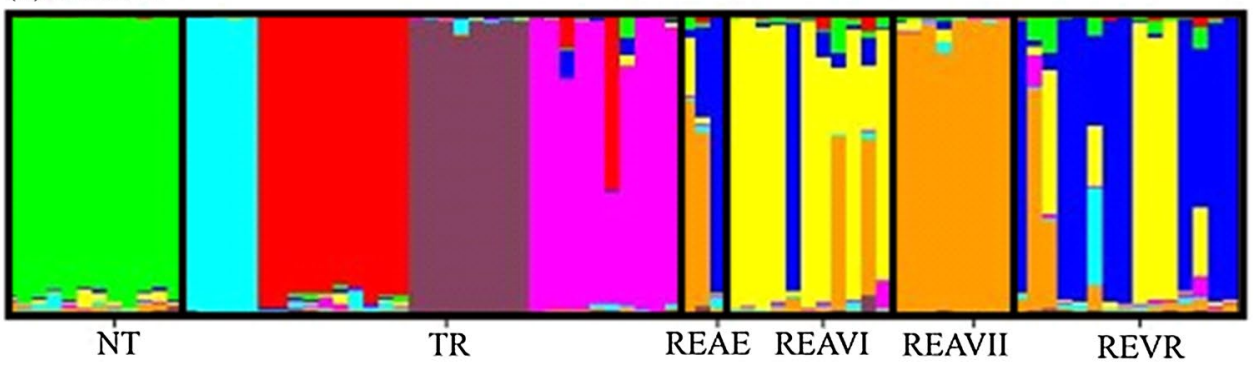

(b) Recent

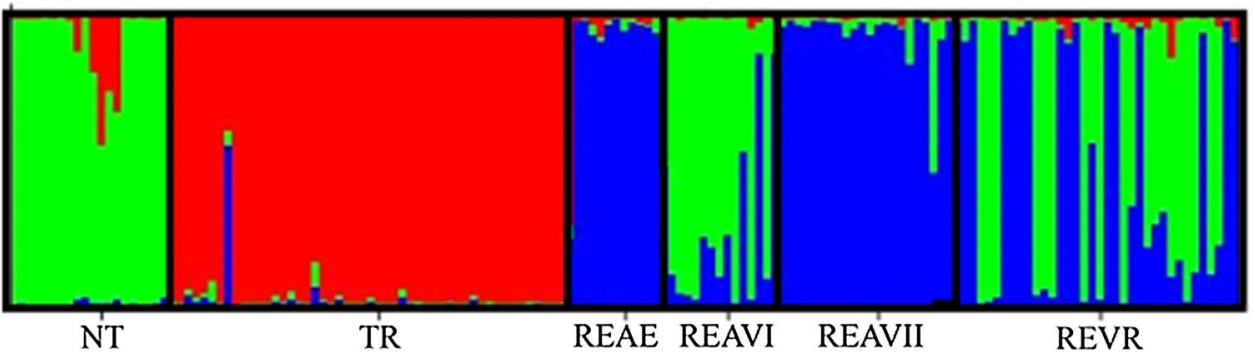

(c) Translocated (TR)

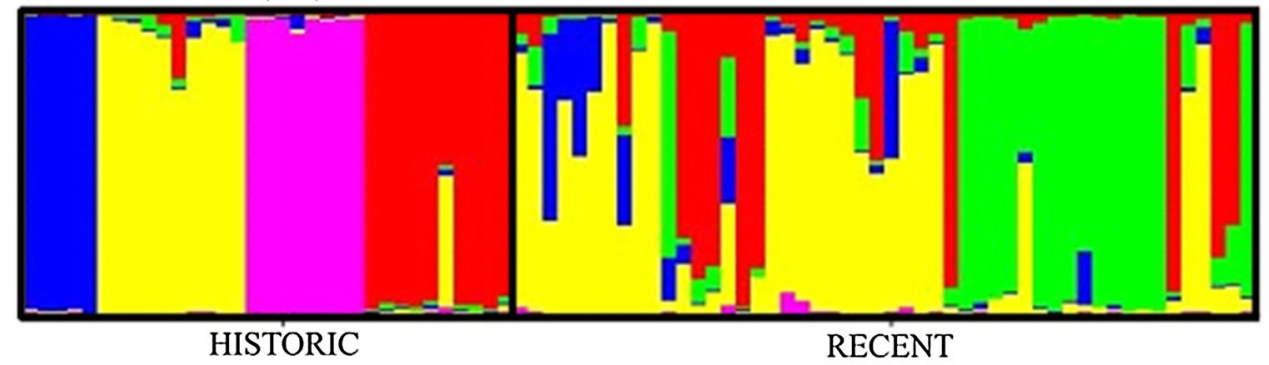

(d) Reintroduced (RE)

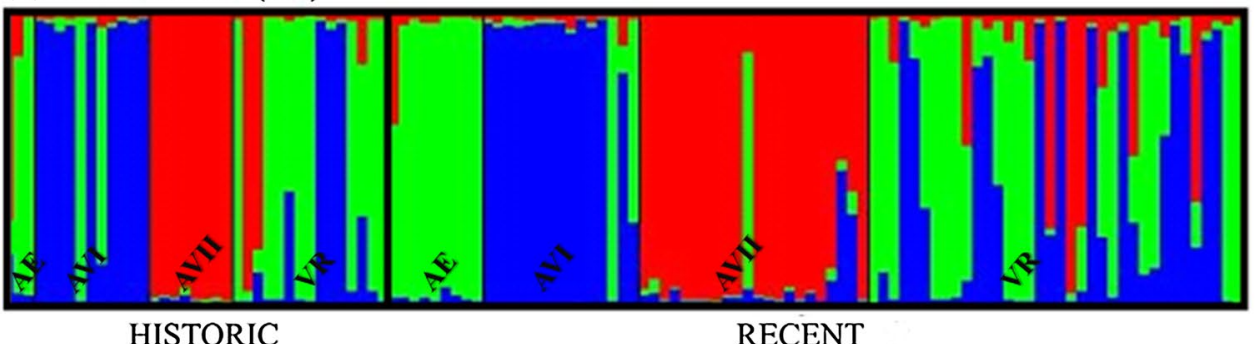

size (Frankham et al. 2010). It comprises both allelic diversity and heterozygosity (Ballou and Foose 2010). When we compared the recent observed heterozygosity among management types, our results showed that the translocated and reintroduced populations had higher heterozygosity rates than the native population. Similarly, when we evaluated the temporal changes in the allele frequencies in the reintroduced and translocated populations in comparison with the native population, our results showed that translocation and reintroduction achieved conservation goals: they maintained or recovered the depleted alleles. Furthermore, translocation recovered private alleles of small and isolated populations that were originally distributed in gallery forests of the SJRB and in restinga forests on the coast of Rio de Janeiro State (Kierulff 2000; Grativol et al. 2001; Kierulff et al. 2002). A similar conclusion was previously reached by Grativol et al. (2001), comparing a smaller sample size of translocated and native $L$. rosalia. In addition, Grativol (2003) reported private haplotypes in the translocated population. However, the possibility that such alleles were not yet sampled in the native population can be not excluded. 
When we evaluated the temporal changes within sites, the heterozygosity at the translocation site increased and the $F_{i s}$ decreased over time, while an inverse tendency was observed in the reintroduction and native sites. On the other hand, the greatest losses of alleles happened in the translocated population, particularly during the first years after translocation. Probably, the main factor responsible for the initial loss of alleles in the translocated population was the mixing of rare alleles in a large population during its establishment (Grativol et al. 2001). Alternatively, these lost alleles may be the result of unsampled descendants of founders in the recent sampling. Similarly, the initial increase in heterozygosity in the translocated population may result from mixing of genetically distinct social groups and may be a recent increase. Since the translocated population remains isolated, and without additional translocations, it is expected to experience drift and inbreeding in the near future (e.g., Kennington et al. 2012).

The second greatest loss of alleles over time was observed in the REVR reintroduction site. Both REVR and the translocation sites are isolated populations, whereas gene flow is probably facilitated by the structural connectivity of the landscape in the other remaining areas (Procópio-de-Oliveira et al. 2008). Even relatively large isolated populations can lose genetic diversity relative to their sources (e.g., Mock et al. 2004). Additionally, the simulation of variation in allelic diversity over time also showed that losses may continue if the translocated population remains isolated over time. If migration is limited and inbreeding continues after founding, the genetic diversity may continue to decline over time (e.g., Kennington et al. 2012). Losses of alleles in the translocated population were greater initially and continued over time. In some cases, loss of alleles are greater initially, when the bottleneck effects are induced by reintroduction or translocation, but they cease over time (e.g., Bristol et al. 2013) if population connectivity is restored.

A similar pattern of losses of alleles was observed in the simulation with the reintroduced population, but was less intense than that observed in the translocated population. Similarly, pedigree analysis showed that the reintroduced $L$. rosalia population retained $96 \%$ of its genetic diversity relative to the source population (Mickelberg 2011). However, some reintroduced sites showed genetic diversity losses and an increase in the $F_{i s}$ over time. At the molecular level, the $F_{i s}$ of the REAVII site (located in Aldeia Velha) increased over time. Similarly at the pedigree level, Aldeia Velha had the largest $F_{i s}$. According to pedigree analysis, the annual mean $F_{i s}$ of reintroduced $L$. rosalia increased most rapidly in the population from 1993 to 2000; thereafter inbreeding was steady, increasing only slightly at an average rate of $0.3 \%$ per year (Mickelberg 2011). Pair-wise comparisons also showed that the reintroduced population had a greater
$F_{i s}$ than the translocated population. The native population also had lower heterozygosity and larger $F_{i s}$ than the translocated population, but it had the lowest loss of the average number of alleles over time (until 2045, see Fig. 3). Moreover, the native as well as REAVII sites showed a decrease of in $H_{o}$ over time only when considering the set 1 analysis, and may be skewed by the family structure of the species.

\section{Temporal genetic structure}

Bayesian cluster analyses showed that population structuring of $L$. rosalia became more site-related over time; probably due to subsequent exposure of the founder populations to the process of genetic drift and isolation promoted by low forest patch connectivity. Reintroduction and translocation programs only have positive effects on demographics and genetic composition if the external factors that limit the population expansion are also controlled (Kleiman 1989). The $\Delta \mathrm{K}$ value was optimal when the wild $L$. rosalia population was strongly structured into two genetic clusters in both historic and recent periods. One cluster was composed of translocated individuals and the other cluster was a combination of native and reintroduced individuals. Differentiation of the translocated population may be the result of early separation from other populations of the species. The majority of the founders of the translocated population represent $L$. rosalia descendants of the coastal Atlantic Forest, which has a distinct physiognomy and is historically isolated by distance (Guedes-Bruni et al. 2006).

On the other hand, the suboptimal $\Delta \mathrm{K}$ values showed the influence of management strategies and of spatial distribution on the population structure. In the historic period, there was a sub-structure in eight genetic clusters that revealed the genetic structure before the translocated population was established, and the mixing between and within reintroduced populations. Congruently, a high proportion of HWE deviations were observed particularly in the translocation site, and historic period, as a consequence of the mixing of different populations, i.e. the Whalund effect (Sinnock 1975). The translocated population was founded by isolated social groups, and the reintroduced populations were founded by the offspring of 33 founders distributed among 30 zoos and genetically managed using pedigree analysis (Kierulff et al. 2002, 2012). Lasting for two generations (11-12 years), this sub-structure was reduced to three genetic clusters-there was a greater homogenization within each management type and distinction between them. These scenarios show the influence of management and the subsequent limitation of gene flow, probably caused by physical barriers in the new habitat.

As we expected, we found no genetic evidence of isolation over time for the native population. Likewise, the reintroduced population showed no evidence of isolation 
over time; however, we observed a tendency toward genetic structuring that corresponds with the release sites. The representation of each site in the within-population structure of reintroduced groups is similar to those indicated by the pedigree analyses (see Mickelberg 2011). Conversely, a change in the genetic structure over time was observed in the translocated population. The greater representation of some translocated groups over others in the recent population suggests a within-population genetic distinction over time (see Fig. 4). Nevertheless, these structuring scenarios could also be the result of the small sample size especially for the historic period (Kalinowski 2011).

\section{Overview for conservation strategies}

Genetic consequences of reintroductions and translocations depend on many local factors that need to be considered on a case-by-case basis. Differences in management between reintroduction and translocation can affect the genetic outcome of the conservation efforts and ultimately the viability measures of the population. For L. rosalia, the reintroduction drew from captive animals managed as one population through a studbook (Ballou and Cooper 1992; Ballou et al. 2002). Animals were also channeled to the wild via "Gateway Zoos" that provided key pre-release experience (Beck and Castro 1994; Stoinski et al. 1997) and the in-situ reintroduction protocols were designed to keep the captiveborn animals alive in the wild until reproduction (Beck et al. 2002). This management procedure likely reduced initial losses of allelic diversity. On the other hand, differential post-release mortality-which was high for the captive-born adult animals (44\% survival to 1-year) and low for their wild-born offspring ( $81 \%$ survival to 1 year of age; Beck et al. 1991, 2002) —and the fragmented structure of the landscape may have contributed to the low gene flow between populations, higher inbreeding coefficient than the translocated population and a trend of lower effective population size over time.

The translocated population was comprised of isolated social groups known to differ in genetic structure, to have low genetic diversity, inbreeding, and rare and private alleles (Grativol et al. 2001). When inbreeding is clearly a factor, the mixture of individuals from different populations is recommended (IUCN/SSC 2013). Because of these characteristics, managers decided to translocate entire social groups of $L$. rosalia to one protected area, as opposed to distributing the groups among existing populations. The groups of $L$. rosalia stayed as cohesive reproductive units after translocation, and reproduction in this population was successful (Kierulff 2000; Kierulff et al. 2002). As a consequence, translocated $L$. rosalia showed a relative decrease in inbreeding over time. Management notwithstanding, the translocated population showed a loss of allelic diversity.
Both populations (translocated and reintroduced) of $L$. rosalia showed an increase in population size, making a significant demographic contribution toward a viable freeliving metapopulation (Kierulff et al. 2002), albeit with some loss of genetic diversity. The genetic analyses of other reintroduced and translocated species, e.g., Antilocapra americana (Stephen et al. 2005), and Meleagris gallopavo merriami (Mock et al. 2004), also showed that these populations grew rapidly but suffered a reduction in their genetic diversity. Future gene flow into these populations via natural dispersal could increase their genetic diversity (as observed by Ortego et al. 2011). We recommend that the success of reintroduction and translocation programs be measured both in terms of demographic and genetic monitoring outcomes.

Reintroduction and translocation programs should carefully consider and include landscape structure in long term planning. Our results indicated a low gene flow among $L$. rosalia populations after translocation and reintroductions. Thus, landscape connectivity influenced genetic diversity and population structure of $L$. rosalia. Furthermore, simulations suggest that if the translocated population of $L$. rosalia continues to be isolated, alleles will continue to be lost over time. Ongoing analyses of functional connectivity will be important to evaluate long-term population viability and to avoid the negative effects of small population size (as observed by Cullingham and Moehrenschlager 2013). We recommend future research on landscape elements that may limit gene flow among $L$. rosalia populations and on measures for reconnection and restoration of their habitats. We suggest that habitat reconnections (Dobson et al. 1999; Bouzat et al. 2009) and restocking (IUCN 1987) be done to promote gene flow among populations of $L$. rosalia. In the case of REVR site, as habitat reconnection is impaired by the BR 101 road, we suggest its supplementation and/ or translocation of some individuals to an unoccupied habitat in the northern of BR 101 road. The translocated site also has a geographically isolated population, although it is surrounded by unoccupied forest patches. We suggest that translocations to these forest patches might increase gene flow and improve the long-term persistence of these populations. The remaining population from the coastal region of Rio de Janeiro (PMLD, Fig. 1) is a possible candidate for animals to translocate. However, a previous genetic analysis of PMLD individuals will be needed to ensure that the genetic diversity in the founder population will be maximized.

The current long-term study indicates that a number of factors-such as the genetic composition and the number of founders, the genetic management of the populations, and the ability of each population to expand quickly and landscape connectivity-can influence the genetic diversity and structure of a population under conservation management. 
If a population has a small size at its founding, low growth rate, and low migration rate, the genetic diversity of the established populations may become reduced following a translocation or a reintroduction (Thrimawithana et al. 2013). Therefore, we recommend monitoring the population genetics before and after a translocation and/or reintroduction, and maintaining population connectivity thereafter to avoid the negative effects of a small population size. Translocation and reintroduction are useful conservation strategies, but they should be done in combination with other strategies (Kleiman 1989) such as habitat restoration, to guarantee a minimum population size and gene flow among the populations.

Acknowledgements We are grateful for support by the LTBF and by K. De Vleeschouwer and P. Galbusera of the Centre for Research and Conservation funded by the Flemish Government. CNPq supported PMG Jr (308385/2014-4), MCR (312045/2013-1) and CRRM (472647/2009-1); and FAPESP supports MCR (2013/50421-2). Scholarship received by AMM (CAPES), CSC (FAPESP 2014/010295) and MCMK (PNPD/CAPES). We thank M. King, a native English speaker, for proofreading the manuscript; A. Nicodemo for assistance in the laboratory; and AMLD, especially A. Martins and P. Procópiode-Oliveira, for providing the field data and hair samples. University of Maryland Animal Care and Use Committee approved protocols for this research. The authors thank the three anonymous reviewers for suggestions and comments, which improved the manuscript.

\section{References}

Allendorf FW (1986) Genetic drift and the loss of alleles versus heterozygosity. Zoo Biol 5:181-190. doi:10.1002/zoo.1430050212

Anderson EC, Dunham KK (2008) The influence of family groups on inferences made with the program structure. Mol Ecol Resour 8:1219-1229. doi:10.1111/j.1755-0998.2008.02355.x

Baker AJ, Dietz JM (1996) Immigration in wild groups of golden lion tamarins (Leontopithecus rosalia). Am J Primatol 38:47-56

Baker AJ, Dietz JM, Kleiman DG (1993) Behavioural evidence for monopolization of paternity in multi-male groups of golden lion tamarins. Anim Behav 46:1091-1103. doi:10.1006/ anbe.1993.1299

Baker AJ, Bales K, Dietz J (2002) Mating system and group dynamics in lion tamarins. In: Kleiman DG, Rylands AB (eds) Lion tamarins: biology and conservation. Smithsonian Inst press, Washington, DC, pp 188-212

Ballou JD, Cooper A (1992) Genetic management strategies for endangered captive populations: the role of genetic and reproductive technology. Symp Zool Soc Lond 64:183-206

Ballou JD, Foose T (2010) Demographic and genetic management of captive populations. In: Kleiman DG, Thompson KV, Baer CK (eds) Wild mammals in captivity. Principles and techniques for zoo management. University of Chicago Press, USA, pp 263-283

Ballou JD, Kleiman DG, Mallinson JJC et al (2002) History, management, and conservation role of the captive lion tamarin populations. In: Kleiman DG, Rylands AB (eds) Lion tamarins: biology and conservation. Smithsonian Inst press, Washington, DC, pp 95-116

Beck BB, Castro MI (1994) Environments for endangered primates. In: Giubbons EF, Wyers E, Waters E, Menzel E (eds)
Naturalistic environments in captivity for animal behavior research. State University of New York, Albany, pp 209-270

Beck BB, Kleiman DG, Dietz JM et al (1991) Losses and reproduction in reintroduced golden lion tamarins, Leontopithecus rosalia. Dodo 27:50-61

Beck BB, Castro MI, Stoinski TS, Ballou JD (2002) The effects of prerelease environments and postrelease management on survivorship in reintroduced golden lion tamarins. In: Kleiman DG, Rylands AB (eds) Lion tamarins: biology and conservation. Smithsonian Inst press, Washington, DC, pp 188-212

Bonin A, Bellemain E, Eidesen PB et al (2004) How to track and assess genotyping errors in population genetics studies. Mol Ecol 13:3261-3273. doi:10.1111/j.1365-294X.2004.02346.x

Bouzat JL, Johnson JA, Toepfer JE et al (2009) Beyond the beneficial effects of translocations as an effective tool for the genetic restoration of isolated populations. Conserv Genet 10:191201. doi:10.1007/s10592-008-9547-8

Brekke P, Bennett PM, Santure AW, Ewen JG (2011) High genetic diversity in the remnant island population of hihi and the genetic consequences of re-introduction. Mol Ecol 20:29-45. doi:10.1111/j.1365-294X.2010.04923.x

Bristol RM, Tucker R, Dawson DA et al (2013) Comparison of historical bottleneck effects and genetic consequences of re-introduction in a critically endangered island passerine. Mol Ecol 22:4644-4662. doi:10.1111/mec.12429

Cain CM, Livieri TM, Swanson BJ (2011) Genetic evaluation of a reintroduced population of black-footed ferrets (Mustela nigripes). J Mammal 92:751-759. doi:10.1644/10-MAMM-S-104.1

Carlsson J (2008) Effects of microsatellite null alleles on assignment testing. J Hered 99:616-623. doi:10.1093/jhered/esn048

Coimbra-Filho AF, Mittermeier RA (1977) Conservation of the Brazilian lion tamarins Leontopithecus rosalia. In: HSH Prince Rainier III of Monaco \& Bourne G (eds) Primate conservation. Academic Press, London, pp 59-94

Cullingham CI, Moehrenschlager A (2013) Temporal analysis of genetic structure to assess population dynamics of reintroduced swift foxes. Conserv Biol 27:1389-1398. doi:10.1111/ cobi.12122

De Barba M, Waits LP, Garton EO et al (2010) The power of genetic monitoring for studying demography, ecology and genetics of a reintroduced brown bear population. Mol Ecol 19:3938-3951. doi:10.1111/j.1365-294X.2010.04791.x

Dietz JM, Baker AJ (1993) Polygyny and female reproductive success in golden lion tamarins, Leontopithecus rosalia. Anim Behav 46:1067-1078

Dietz JM, Baker AJ, Miglioretti D (1994) Seasonal variation in reproduction, juvenile growth, and adult body mass in golden lion tamarins (Leontopithecus rosalia). Am J Primatol 34:115-132. doi:10.1002/ajp.1350340204

Do C, Waples RS, Peel D et al (2014) NeEstimator v2: re-implementation of software for the estimation of contemporary effective population size $(\mathrm{Ne})$ from genetic data. Mol Ecol Resour 14:209-214. doi:10.1111/1755-0998.12157

Dobson A, Ralls K, Foster M et al (1999) Corridors: reconnecting fragmented landscapes. In: Soulé ME, Terborgh J (eds) Continental conservation: scientific foundations of regional reserve networks. Island Press, Washington, DC, pp 129-170

Earl DA, vonHoldt BM (2012) STRUCTURE HARVESTER: a website and program for visualizing STRUCTURE output and implementing the Evanno method. Conserv Genet Resour 4:359-361. doi:10.1007/s12686-011-9548-7

Evanno G, Regnaut S, Goudet J (2005) Detecting the number of clusters of individuals using the software STRUCTURE: a simulation study. Mol Ecol 14:2611-2620. doi:10.1111/j.1365-294X.2005.02553.x 
Fischer J, Lindenmayer DB (2000) An assessment of the published results of animal relocations. Biol Conserv 96:1-11. doi:10.1016/S0006-3207(00)00048-3

Frankham R (1995) Effective population size/adult population size ratios in wildlife: a review. Genet Res 66:95-107. doi:10.1017/ S0016672308009695

Frankham R, Ballou J, Briscoe DA (2010) Introduction to conservation genetics, 2nd edn. Cambridge University Press, New York

Franklin IR, Frankham R (1998) How large must populations be to retain evolutionary potential? Anim Conserv 1:69-70

Galbusera PHA, Gillemot S (2008) Polymorphic microsatellite markers for the endangered golden-headed lion tamarin, Leontopithecus chrysomelas (Callitrichidae). Conserv Genet 9:731733. doi:10.1007/s10592-007-9370-7

Goudet J (2005) HIERFSTAT, a package for R to compute and test hierarchical F-statistics. Mol Ecol Notes 2:184-186. doi:10.1111/j.1471-8278.2004.00828.x

Grativol AD (2003) DNA antigo e genética da conservação do mico-leão-dourado (Leontopithecus rosalia): estrutura genética em duas escalas de tempo e sua relação com a fragmentação da Mata Atlântica. Acad. Thesis, Universidade Estadual do Norte Fluminense

Grativol AD, Ballou JD, Fleischer RC (2001) Microsatellite variation within and among recently isolated populations of golden lion tamarins (Leontopithecus rosalia). Conserv Genet 2:1-9

Griffith B, Scott J, Carpenter J, Reed C (1989) Translocation as a species conservation tool: status an strategy. Science 245:477-480

Guedes-Bruni RR, Silva Neto SJ da, Morim MP, Mantovani W (2006) Composição florística e estrutura de dossel em trecho de Floresta Ombrófila Densa Atlântica sobre morrote mamelonar na Reserva Biológica de Poço das Antas, Silva Jardim, Rio de Janeiro, Brazil. Rodriguésia 57:429-442

Habel JC, Husemann M, Finger A et al (2014) The relevance of time series in molecular ecology and conservation biology. Biol Rev 89:484-492. doi:10.1111/brv.12068

Holst B, Medici E, Marinho-Filho O et al (2006) Lion tamarin population and habitat viability assessment workshop2005: final report. Apple Valley, MN, USA

ICMBio (2016) Unidades de Conservação. http://www.icmbio.gov.br/ portal/unidades-de-conservacao.html. Accessed 15 Jan 2016

IUCN (1987) The IUCN position statement on translocation of living organisms: introductions, re-introductions and re-stocking. https://portals.iucn.org/library/node/6507. Accessed 30 Sep 2016

IUCN/SSC (2013) Guidelines for reintroductions and other conservation translocations. Version 1.0. Gland, IUCN Species Survival Commission, Switzerland

Jorde PE, Ryman N (2007) Unbiased estimator for genetic drift and effective population size. Genetics 177:927-935. doi:10.1534/ genetics.107.075481

Kalinowski ST (2005) HP-RARE 1.0: a computer program for performing rarefaction on measures of allelic richness. Mol Ecol Notes 5:187-189. doi:10.1111/j.1471-8286.2004.00845.x

Kalinowski ST (2011) The computer program STRUCTURE does not reliably identify the main genetic clusters within species: simulations and implications for human population structure. Heredity 106:625-632. doi:10.1038/hdy.2010.95

Kamath PL, Haroldson MA, Luikart G et al (2015) Multiple estimates of effective population size for monitoring a long-lived vertebrate: an application to Yellowstone grizzly bears. Mol Ecol 24:5507-5521. doi:10.1111/mec.13398

Kennington WJ, Hevroy TH, Johnson MS (2012) Long-term genetic monitoring reveals contrasting changes in the genetic composition of newly established populations of the intertidal snail Bembicium vittatum. Mol Ecol 21:3489-3500. doi:10.1111/j.1365-294X.2012.05636.x
Kierulff MCM (2000) Ecology and Behavior of translocated groups of golden lion tamarin (Leontopitehcus rosalia). Acad. Thesis, University of Cambridge

Kierulff MCM, Procópio-de-Oliveira P (1996) Re-assessing the status and conservation of the golden lion tamarin (Leontopithecus rosalia) in wild. Dodo J Jersey Wildl Preservation Trust 32:98-115

Kierulff MCM, Rylands AB (2003) Census and distribution of the golden lion tamarin (Leontopithecus rosalia). Am J Primatol 59:29-44. doi:10.1002/ajp.10064

Kierulff MCM, Procópio-de-Oliveira PP, Beck BB et al (2002) Reintroduction and translocation as conservation tools for golden lion tamarins. In: Kleiman DG, Rylands AB (eds) Lion tamarins: biology and conservation. Smithsonian Inst press, Washington, DC, pp 271-282

Kierulff MCM, Rylands AB, Procópio-de-Oliveira MM (2008) Leontopithecus rosalia. The IUCN Red List of Threatened Species 2008: e T11506A3287321. http://dx.doi.org/10.2305/IUCN. UK.2008.RLTS.T11506A3287321.en. Acessed 07 March 2016

Kierulff MCM, Ruiz-Miranda CR, Procópio-de-Oliveira $\mathrm{P}$ et al (2012) The Golden lion tamarin Leontopithecus rosalia: a conservation success story. Int Zoo Yearb 46:36-45. doi:10.1111/j.1748-1090.2012.00170.x

Kleiman D (1989) Reintroduction of captive mammals for conservation. Bioscience 39:152-161. doi:10.2307/1311025

Kleiman DG, Beck BB, Dietz JM et al (1986) Conservation program for the golden lion tamarin: captive research and management, ecological studies, educational strategies, and reintroduction. In: Benirhke K (ed) Primates. Springer-Verlag New York Inc., New York, pp 959-979

Kuo CH, Janzen FJ (2003) BOTTLESIM: a bottleneck simulation program for long-lived species with overlapping generations. Mol Ecol Notes 3:669-673. doi:10.1046/j.1471-8286.2003.00532.x

Maruyama T, Fuerst PA (1985) Population bottlenecks and nonequilibrium models in population genetics. II. Number of alleles in a small population that was formed by a recent bottleneck. Genetics 111:675-689

Meirmans PG (2015) Seven common mistakes in population genetics and how to avoid them. Mol Ecol 24:3223-3231. doi:10.1111/ mec. 13243

Michaelides S, Cole N, Funk SM (2015) Translocation retains genetic diversity of a threatened endemic reptile in Mauritius. Conserv Genet 16:661-672. doi:10.1007/s10592-014-0691-z

Mickelberg JL (2011) Understanding and managing isolation in a fragmented population of golden lion tamarins, Leontopithecus rosalia. Dissertation, George Mason University

Mock KE, Latch EK, Rhodes OE (2004) Assessing losses of genetic diversity due to translocation: Long-term case histories in Merriam's turkey (Meleagris gallopavo merriami). Conserv Genet 5:631-645. doi:10.1007/s10592-004-1849-x

Mowry RA, Schneider TM, Latch EK et al (2015) Genetics and the successful reintroduction of the Missouri river otter. Anim Conserv 18:196-206. doi:10.1111/acv.12159

Ortego J, Yannic G, Shafer ABA et al (2011) Temporal dynamics of genetic variability in a mountain goat (Oreamnos americanus) population. Mol Ecol 20:1601-1611. doi:10.1111/j.1365-294X.2011.05022.x

Parker KA (2008) Translocations: providing outcomes for wildlife, resource managers, scientists, and the human community. Restor Ecol 16:204-209. doi:10.1111/j.1526-100X.2008.00388.x

Peakall R, Smouse PE (2006) GENALEX 6: genetic analysis in Excel. Population genetic software for teaching and research. Mol Ecol Notes 6:288-295. doi:10.1111/j.1471-8286.2005.01155.x

Perez-Sweeney BM, Valladares-Padua C, Burrell AS et al (2005) Dinucleotide microsatellite primers designed for a critically endangered primate, the black lion tamarin 
(Leontopithecus chrysopygus). Mol Ecol Notes 5:198-201. doi:10.1111/j.1471-8286.2005.00875.x

Pritchard JK, Stephens M, Donnelly P (2000) Inference of population structure using multilocus genotype data. Genetics 155:945-959. doi:10.1111/j.1471-8286.2007.01758.x

Procópio-de-Oliveira P, Grativol A, Ruiz-Miranda C (2008) Conservação do mico-leão-dourado: enfrentando os desafios de uma paisagem fragmentada. Universidade Estadual do Norte Fluminense Darcy Ribeiro press, Campos dos Goytacazes, RJ, Brazil

R Development Core Team (2015) R: A language and environment for statistical computing. R Foundation for Statistical Computing, Vienna, Austria. http://www.R-project.org/

Ribeiro MC, Metzger JP, Martensen AC et al (2009) The Brazilian Atlantic Forest: How much is left, and how is the remaining forest distributed? Implications for conservation. Biol Conserv 142:1141-1153. doi:10.1016/j.biocon.2009.02.021

Rice WR (1989) Analyzing tables of statistical tests. Evolution Int J Org Evolution 43:223-225

Sasmal I, Jenks JA, Waits LP et al (2013) Genetic diversity in a reintroduced swift fox population. Conserv Genet 14:93-102. doi:10.1007/s10592-012-0429-8

Schuelke M (2000) An economic method for the fluorescent labeling of PCR fragments. Nat Biotechnol 18:233-234

Schwartz MK, McKelvey KS (2009) Why sampling scheme matters: the effect of sampling scheme on landscape genetic results. Conserv Genet 10:441-452. doi:10.1007/s10592-008-9622-1

Seddon PJ, Armstrong DP, Maloney RF (2007) Developing the science of reintroduction biology. Conserv Biol 21:303-312. doi:10.1111/j.1523-1739.2006.00627.x

Sigg DP, Goldizen AW, Pople AR (2005) The importance of mating system in translocation programs: reproductive success of released male bridled nailtail wallabies. Biol Conserv 123:289300. doi:10.1016/j.biocon.2004.11.017

Sinnock P (1975) The wahlund effect for the two-locus model. Am Nat 109:565-569. doi:10.2307/2678832

Stephen C, Whittaker D, Gillis D et al (2005) Genetic consequences of reintroductions: an example from oregon pronghorn antelope
(Antilocapra americana). J Wildl Manage 69:1463-1474. doi:10.2193/0022-541X(2005)69[1463:GCORAE]2.0.CO;2

Stoinski TS, Beck BB, Bowman MD, Lenhardt J (1997) The gateway zoo program: a recent initiative in golden lion tamarin reintroductions. In: Wallis J (ed) Primate conservation: the role of zoological parks. American Society of Primatologists, Norman, OK, pp 113-130

Thrimawithana AH, Ortiz-Catedral L, Rodrigo A, Hauber ME (2013) Reduced total genetic diversity following translocations? A metapopulation approach. Conserv Genet 14:1043-1055. doi:10.1007/s10592-013-0494-7

Tollington S, Jones CG, Greenwood A et al (2013) Long-term, finescale temporal patterns of genetic diversity in the restored Mauritius parakeet reveal genetic impacts of management and associated demographic effects on reintroduction programmes. Biol Conserv 161:28-38. doi:10.1016/j.biocon.2013.02.013

Van Oosterhout C, Hutchinson WF, Wills DPM, Shipley P (2004) MICRO-CHECKER: software for identifying and correcting genotyping errors in microsatellite data. Mol Ecol Notes 4:535538. doi:10.1111/j.1471-8286.2004.00684.x

Wang J (2005) Estimation of effective population sizes from data on genetic markers. Philos Trans R Soc Lond B Biol Sci 360:13951409. doi:10.1098/rstb.2005.1682

Waples RS (2005) Genetic estimates of contemporary effective population size: to what time periods do the estimates apply? Mol Ecol 14:3335-3352. doi:10.1111/j.1365-294X.2005.02673.x

Waples RS (2006) A bias correction for estimates of effective population size based on linkage disequilibrium at unlinked gene loci. Conserv Genet 7:167-184. doi:10.1007/s10592-005-9100-y

Waples RS, Do C (2008) LDNE: a program for estimating effective population size from data on linkage disequilibrium. Mol Ecol Resour 8:753-756. doi:10.1111/j.1755-0998.2007.02061.x

Waples RS, Do C (2010) Linkage disequilibrium estimates of contemporary Ne using highly variable genetic markers: a largely untapped resource for applied conservation and evolution. Evol Appl 3:244-262. doi:10.1111/j.1752-4571.2009.00104.x 